\title{
Are Fetuses Affected by Gastroschisis Benefited from Prenatal Maternal Corticosteroid Use and Early Parturition?
}

\author{
Mateus Guimarães Massimo¹, Anna Paula Auada Kopaz ${ }^{1}$, Neil Ferreira Novo², \\ Willy Marcus França ${ }^{1,3^{*}}$ \\ ${ }^{1}$ Medical Science and Health Faculty, PUC/SP (FCMS, PUC/SP), Sorocaba, Brazil \\ ${ }^{2}$ Department of Medicine, Service of Statistical Studies of PUC/SP, Sorocaba, Brazil \\ ${ }^{3}$ Medical Science and Health Faculty, The Laboratory of Surgery Technique and Experimental Surgery of FCMS, PUC/SP, \\ Sorocaba, Brazil \\ Email: *willy@drwilly.com.br
}

How to cite this paper: Massimo, M.G., Kopaz, A.P.A., Novo, N.F. and França, W.M. (2019) Are Fetuses Affected by Gastroschisis Benefited from Prenatal Maternal Corticosteroid Use and Early Parturition? Surgical Science, 10, 154-163. https://doi.org/10.4236/ss.2019.105019

Received: March 21, 2019

Accepted: May 26, 2019

Published: May 29, 2019

Copyright ( 2019 by author(s) and Scientific Research Publishing Inc. This work is licensed under the Creative Commons Attribution International License (CC BY 4.0).

http://creativecommons.org/licenses/by/4.0/

\section{(c) () Open Access}

\begin{abstract}
Introduction: Gastroschisis (G) is a congenital defect of the abdominal walls through which intestinal herniation and permanent exposure to amniotic liquid (AL) and its components are developed at the end of gestation. $\mathrm{G}$ affects mostly fetuses from young mothers under $25-29$ years old, but it occurs more often in fetuses of mothers' ages between 12 - 15 years old. Some authors assert that it is not the low weight, nor the low gestational age that influences mortality. In addition to morphological alterations, histological alterations are characterized by disorganization, distribution and the degree of ganglia maturity and myenteric plexuses. The literature describes parturition anticipation of $\mathrm{G}$ disease carriers to minimize damages to intestinal loops. There are studies suggesting corticosteroids at the end of gestation in order to avoid morphological and histological damages to the intestinal loop. Objective: Identify if live newborn infants delivery anticipation, that is, gestational date less than 37 weeks and prenatal maternal use of corticosteroid were benefited from early enteral diet, namely, less than 10 post-surgery days. Material and Method: From 33 newborns researched in the period from 2010 to 2014; 28 newborns full records were included in the study with $15.2 \%$ mortality rate. These newborns were divided in 3 groups according to maternal age: 6 newborns from mothers' age between 16 - 20 years old (Group 1); 14 newborns from mothers' age between $21-25$ years old (Group 2) and 8 newborns from mothers' age between 26 - 29 years old (Group 3). Gestational age at birth and prenatal maternal usage of corticosteroid and beginning oral feed-
\end{abstract}


ing were assessed. Results: From 28 newborns, 19 mothers ingested prenatal corticosteroid and 16 newborns received the first enteric diet 10 days before and 3 days later. The mothers of the other 9 newborns were not treated with corticosteroid; only 3 newborns were fed before 10 days and 6 were fed later $(p=0.0016)$. Regarding gestational age, 17 newborns were born before 37 weeks and their $1^{\text {st }}$ enteral diet was offered before 10 days. From the 11 newborns born after 37 weeks, only 4 received the $1^{\text {st }}$ enteral diet before 10 days $(p=0.015)$. Conclusion: Newborn infants born with gestational age below 37 weeks, whose mothers received prenatal corticosteroid, were benefited with the first enteral diet before 10 postoperative days.

\section{Keywords}

Gastroschisis, Preterm Delivery, Maternal Use of Corticosteroid, First Enteral Feeding

\section{Introduction}

Gastroschisis (G) is a congenital defect of the abdominal wall characterized by a small orifice usually at the right side of the umbilical scar that allows permanent exposure of intestinal loops to the amniotic liquid [1] [2]. Ultrasonography can diagnose $\mathrm{G}$ in the prenatal period, but it can also assess ultrasonographic markers of after birth evolution of neonates affected by G [3]. G occurs in 1:5000 up to 1:10,000 liveborn, reaching 2.6 cases per 10,000 births and affects more boys than girls (2 to 1) [4] [5]. Despite that gastroschisis is known as an isolated anomaly, publications show an increased incidence congenital heart defects [6].

Although young maternal age has been identified as a risk factor for G, pregnancy loss and Chlamydia exposure in young women (16 - 25 years old) seem to be risk factors for $\mathbf{G}(p<0.002)$ [7] [8]. Despite the unknown etiology mechanism of formation of paraumbilical congenital defect in $\mathrm{G}$, some authors suggest that the defect might occur through regression or precocious lesion of one of the omphalomesenteric arteries in the embryonic phase [9] through genetic teratogenic alterations and/or drugs, such as acetylsalicylic acid, pseudoephedrine, and acetaminophen and smoking habit would also be involved in its etiology [10].

According to Di Lorenzo et al., 1987, neither low weight nor gestational weight influences mortality [11]. On the other hand, Vilela PC et al., 2001 assert that low birth weight increases 3 times the risk of death of newborn G carriers [12]. G mortality rates differ according to authors and vary from $13 \%$ to $52 \%$ [11] [12].

Permanent exposure of amniotic liquid on loops and their components causes morphological and histological alterations on the intestinal wall, such as wall thickening and contraction of intestinal loops resulting in intestinal hypomotility, due to immaturity of myoenteric plexus, and deficiency of nutrients absorption [13] [14] [15]. Formation of a thin fibrin layer (fibrous peel or fibrous coat- 
ing) also occurs with a certain rate over the serous membrane that favors the development of adherence between intestinal loops that harmed even more the bowel movements (motility) [16] [17].

Elective preterm delivery has been suggested in the literature to prevent demise and ameliorate intestinal injury in fetus with $\mathbf{G}$ because it appears to be favorable with respect to feeding and sepsis [18]. Prelabor cesarian section seems to be beneficial for infants with G, but only don't decrease length of stay [19].

The use of corticosteroid such as dexamethasone during gestation in experimental studies increases the level of disaccharidase enzyme and lactate that can have any effect in the intestinal inflammatory response and improve its maturity [20] [21].

The present study aims to identify if live Newborn Infants (NI) delivery anticipation (gestational date less than 37 weeks) and prenatal maternal use of corticosteroid was beneficial for early enteral diet, namely, less than 10 post-surgery days [22] [23].

\section{Material and Method}

This study was approved by the Ethics Committee of the Medical Science and Health Faculty, Catholic University of São Paulo, Brazil.

From 33 newborn infants diagnosed with $\mathrm{G}$ in the prenatal period by maternal ultrasonography from January 2010 to December 2014, 28 newborns presented isolated G (uncomplicated, Figure 1(a)), that is, there were no associated malformations. Other 5 newborns presented solid distribution of fibrin on intestinal loops, as well as solid adherences and additional associated malformations that complicated their evolution regardless of G (complicated, Figure 1(b)) [22]. Consequently, those 5 newborns were excluded from the study. Twenty eight newborns records with isolated $\mathrm{G}$ contained enough data for a full analysis. From those, 2 newborns died before 3 days of life and other 3 newborns died before one month of life (12, 23 and 28 days of life), whom would probably be part of complex G cases (15.2\%) [22]. Twenty eight (28) newborns records were divided in 3 groups according to maternal age: 6 newborns of mothers' ages between 15 and 20 years old (Group 1, G1); 14 newborns of mothers' age between 21 and 25 years old (Group 2, G2); and 8 newborns with mothers' age between 26 and 29 years old (Group 3, G3) (Figure 2) [7] [8]. The following parameters were assessed: Parturition Gestational Age (GA) and maternal use of prenatal corticosteroid and enteral diet introduction 10 days of post-surgery or greater or equal to 10 post-surgery [18] [23]. All newborns were submitted to a surgical

Given that the sample is relatively small, 3 groups were analyzed altogether with regards to GA relation and the first enteral diet and maternal corticosteroid usage. Spearmann Correlation Coefficient was used in statistic calculations for GI x Enteral Diet, and Fisher Exact Test for Corticosteroid x Enteral Diet analysis. Intervals of $p<0.05$ were considered statistically significant. All patients were undergone to surgical procedure into 24 hours after birth. 


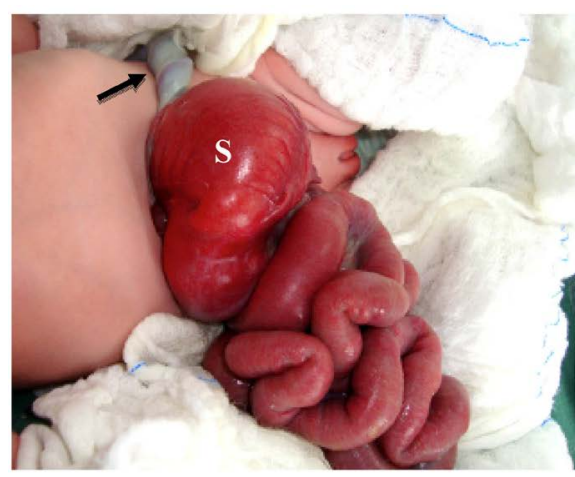

(a)

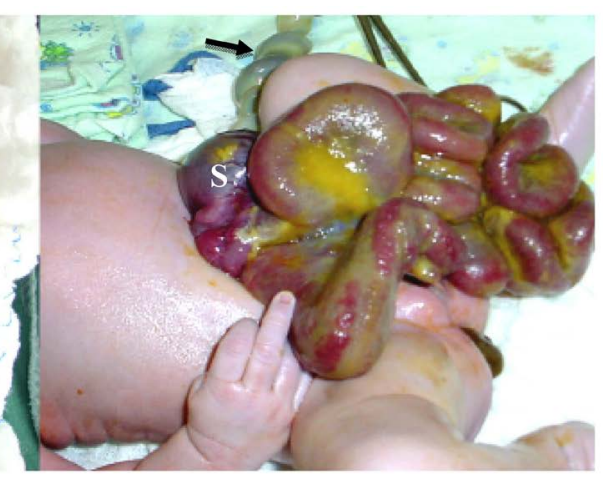

(b)

Figure 1. (a) G intestinal loops without fibrin layer of a 35-week gestation newborn. Note the stomach (S) on the left side and the umbilical cord (arrows); (b) shows the presence of a yellow thin fibrin layer covering almost the whole surface of the loops.

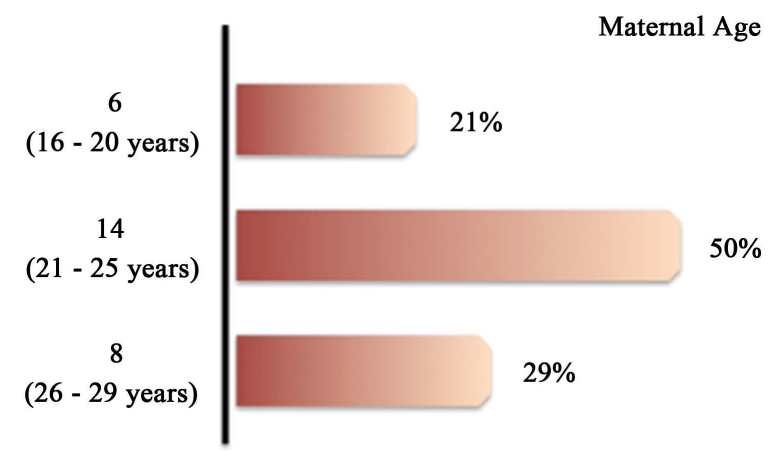

Figure 2. G distribution according to maternal age in years.

\section{Results}

From 28 newborns, 6 were born from 16 - 20 years old mothers (G1, 21\%). Other 14 newborns were brought forth by mothers whose ages were 21 - 25 years old (G2, 50\%), and 8 other newborns were delivered by mothers whose ages were 26 - 29 years old (G3, 29\%) (Figure 2).

In the G1 4 newborns were delivered before 37 weeks of gestation and 2 were delivered after 37 weeks. All the mothers of the 4 newborns delivery before 37 weeks were treated with prenatal corticosteroid (dexamethasone). Those same 4 newborns received the $1^{\text {st }}$ enteral feeding up to 10 days after birth ( 8 - 10 days). Concerning the mothers of the 2 other babies that were born after 37 weeks, one of them were treated with a prenatal corticosteroid and the other mother were not treated. All mothers who delivered before 37 weeks of GA and were treated with prenatal corticosteroid had their babies fed the first enteral diet before 10 post-operative days (Table 1).

In G2, 8 infants were born before 37 weeks of gestation. Mothers of 6 newborns were treated with corticosteroid in the prenatal period. Among them, only one newborn didn't receive the first enteral diet before 10 post-operative days and was fed only on the $13^{\text {th }}$ day. The other 6 infants that were born after 37 weeks, 4 mothers were treated with prenatal corticosteroid, and 3 of them received 
Table 1. Shows the distribution of 6 newborns in G1. It also shows NI whose mothers received prenatal corticosteroid and the period they received the first enteral feeding.

\begin{tabular}{|c|c|c|c|c|c|c|}
\hline \multirow{3}{*}{$\mathrm{RN}$} & \multicolumn{6}{|c|}{ G1 } \\
\hline & \multicolumn{2}{|c|}{ Delivery Period } & \multicolumn{2}{|c|}{ Corticosteroid } & \multicolumn{2}{|c|}{ Feeding } \\
\hline & $<37$ weeks & $\geq 38$ weeks & Yes & No & $<10$ days & $>11$ days \\
\hline 1 & 35 & & + & & 8 & \\
\hline 2 & 37 & & + & & 8 & \\
\hline 3 & 35 & & + & & 9 & \\
\hline 4 & 36 & & + & & 10 & \\
\hline 5 & & 39 & & + & & 12 \\
\hline 6 & & 38 & + & & & 14 \\
\hline Partial & 4 & 2 & 5 & 1 & 4 & 2 \\
\hline Total & \multicolumn{2}{|c|}{6} & \multicolumn{2}{|c|}{6} & \multicolumn{2}{|c|}{6} \\
\hline
\end{tabular}

their first enteral diet until the $10^{\text {th }}$ day, and only one of them was fed later on the $14^{\text {th }}$ day. From 10 newborns in G2, whose mothers received prenatal corticosteroid, 8 of them started a diet via oral until the $10^{\text {th }}$ post-operative day. Among the 14 newborns in G2 only 5 mothers who delivered before 37 weeks of GA and were treated with prenatal corticosteroid had their babies fed the first enteral diet before 10 post-operative days (Table 2).

In G3, 5 infants were born before 37 weeks of gestation. From those, the mothers of 4 newborns were treated with prenatal corticosteroid and their babies received the first enteral diet before 10 post-operative days. From 3 infants that were born after 37 weeks of gestation only one mother received prenatal corticosteroid; nevertheless, this newborn was fed only in the $16^{\text {th }}$ post-surgical day.

Distribution of 8 NI of G3 in which only 4 of them were delivered simultaneously before 37 weeks and mothers received prenatal corticosteroid and the first enteral diet was given before 10 days. Among other 3 NI who were born after 37 weeks only one the mother has received corticosteroid, but he was feed within 16 days post-op (Table 3 ).

From 28 newborns infants, 19 mothers used prenatal corticosteroid. From these, 16 newborns received the first enteral diet before the $10^{\text {th }}$ post-operative day and 3 of them later on. In the present study, the parturition type wasn't considered, nor was the type of $\mathrm{G}$ correction, be it primary suture or use silo. Among the other 9 newborns whose mothers did not take prenatal corticosteroid, only 3 of them received the first enteral diet before the $10^{\text {th }}$ post-operative day and 6 newborns received the first enteral diet after the $10^{\text {th }}$ day post-operative. Using Fisher Exact Test for small samples and non-parametric data, the two groups were compared. The result showed statistical significant difference $p=$ 0.0016

From 28 newborns, 17 were born before 37 weeks of gestation and received the first enteral diet before the $10^{\text {th }}$ post-operative day. Within the 11 newborns born after 37 weeks, only 4 were first fed before 10 days ( $p=0.015)$. 
Table 2. Shows the distribution of 14 newborns in G2. It also shows 9 newborns whose mothers received prenatal corticosteroid and the period they received enteral feeding.

\begin{tabular}{|c|c|c|c|c|c|c|}
\hline \multirow{3}{*}{ Newborn } & \multicolumn{6}{|c|}{ G2 } \\
\hline & \multicolumn{2}{|c|}{ Delivery Period } & \multicolumn{2}{|c|}{ Corticosteroid } & \multicolumn{2}{|c|}{ Feeding } \\
\hline & $<37$ weeks & $\geq 38$ weeks & Yes & No & $<10$ days & $>11$ days \\
\hline 1 & & 37 & + & & 10 & \\
\hline 2 & & 37 & & + & 9 & \\
\hline 3 & & 39 & + & & 9 & \\
\hline 4 & 34 & & + & & 8 & \\
\hline 5 & 34 & & & + & & 12 \\
\hline 6 & 36 & & + & & 9 & \\
\hline 7 & & 40 & + & & & 14 \\
\hline 8 & & 38 & & + & & 18 \\
\hline 9 & 36 & & + & & 9 & \\
\hline 10 & 35 & & + & & 10 & \\
\hline 11 & 36 & & & + & 9 & \\
\hline 12 & 35 & & + & & & 13 \\
\hline 13 & & 39 & + & & 10 & \\
\hline 14 & 35 & & + & & 8 & \\
\hline Partial & 8 & 6 & 10 & 4 & 10 & 4 \\
\hline Total & & & & & & \\
\hline
\end{tabular}

Table 3. Shows the distribution of 8 NI of G3 in which only 4 of them were delivered simultaneously before 37 weeks. The mothers received prenatal corticosteroid and received the first enteral diet before 10 days.

\begin{tabular}{|c|c|c|c|c|c|c|}
\hline \multirow{3}{*}{ Neonate } & \multicolumn{6}{|c|}{ G3 } \\
\hline & \multicolumn{2}{|c|}{ Delivery Period } & \multicolumn{2}{|c|}{ Corticosteroid } & \multicolumn{2}{|c|}{ Feeding } \\
\hline & $<37$ weeks & $\geq 37$ weeks & Yes & No & $<10$ days & $>11$ days \\
\hline 1 & 35 & & + & & 10 & \\
\hline 2 & 35 & & + & & 10 & \\
\hline 3 & 37 & & & + & 8 & \\
\hline 4 & 35 & & + & & 9 & \\
\hline 5 & & 38 & & + & & 12 \\
\hline 6 & & 40 & + & & & 16 \\
\hline 7 & 36 & & + & & 9 & \\
\hline 8 & & 39 & & + & & 14 \\
\hline Partial & 5 & 3 & 5 & 3 & 5 & 3 \\
\hline Total & & & & & & \\
\hline
\end{tabular}


In order to accomplish an accurate analysis between delivery anticipation $(<37$ weeks), prenatal corticosteroid use and maternal nursing before 10 days of life there was the need to gather the data from the 3 groups. The latter was possible by using Spearman correlation coefficient (Rs) to compare delivery gestational age and onset of maternal nursing. This correlation of 0.45 was statistically significant different with $p=0.0150$.

In order to compare the $3 \mathrm{NI}$ groups concerning the utilization of prenatal corticosteroid and its relation with nourishment before 10 days of life, Exact Fisher's Test was applied. The result was statistically significant different with $p$ $=0.0016($ Table 4$)$.

\section{Discussion}

$\mathrm{G}$ lesions in the intestine and their consequent morphologic and histological lesions bring grave disturbances to intestinal dysmotility due to neuronal immaturity that hampers breastfeed outset [13] [14]. This dysmotility is related to intestinal morphological and histological lesions and it is associated with the time of exposure of the intestinal loops to AL. Moreover, anticipation of delivery and prenatal corticosteroid use could reduce these lesions and facilitate a more precocious enteral nourishment [14]. The use of prenatal corticosteroid would improve the activity of disaccharidase on the intestinal mucosa and nutrients acceptance by a portion of the intestine [18].

Anticipation of delivery to the detriment of prematurity risks to NI G carriers is described in order to minimize damages caused to intestinal loops [14] [17], especially the formation of a fibrin layer (fibrous peel or fibrous coating) that occurs in the majority of full term NI [21]. Others suggest the use of corticosteroid, such as dexamethasone, at the end of gestation reduces intestinal weight by phenomena inhibition, such as edema and fibrin deposition [18]. Maternal age could be another G complex factor; but despite the literature attesting that, regardless of the use of maternal age between 25 - 29 years old as reference, G prevalence is 4.2 times greater between 12 - 15 years old (95\%). In the current study, $50 \%$ of G cases occurred between 21 - 25 years old and other $29 \%$ whose ages were between 21 - 25 years old [4]. Only $21 \%$ were minors whose age was below 16 years old.

Table 4. Shows NI numbers in 3 groups of mothers that took prenatal corticosteroid who were fed before 10 post-surgery days.

\begin{tabular}{ccccc}
\hline \multirow{2}{*}{ Corticosteroid } & \multicolumn{4}{c}{ Feeding Day } \\
\cline { 2 - 5 } & $<10$ days & $\geq 10$ days & Total & $\%<10$ days \\
\hline yes & 16 & 3 & 19 & $84.2 \%$ \\
no & 3 & 6 & 9 & $33.3 \%$ \\
Total & 19 & 9 & 28 & \\
& & & & $\mathbf{p}=\mathbf{0 . 0 0 1 6}$ \\
\hline
\end{tabular}


In the literature, parturient gestational age varies between 36 [5] and 36.8 [19] weeks that is similar to the current study, in which the average was up to 36.6 weeks. In isolated G, as described in this study, delivery GA average was 36.6 weeks, datum similar to international literature data, whereas Lap CCMM et al. suggest that, 2016 gestational age was $36.1( \pm 1.4)$ weeks [22].

In this same metanalysis study published by 25 medical centers with 1652 study cases, complete enteral diet was offered on average within 26 days (range 6 and 515) [22]. In the present study, the average of days to start enteral diet was of 10.6 days, that is, within the interval shown in the study, especially the NI whose mothers used prenatal corticosteroid $(16,84.2 \%)$ when compared to NI whose mothers didn't use prenatal corticosteroid $(9,33.3 \%)$ statistically significant different with $p=0.002$. Studies published in the literature attested that the first enteral diet started about 12 days of life (52.1\%), whereas $58.3 \%$ received the first enteral diet after this date.

Delivery anticipation before 37 weeks of gestation was shown to be beneficial to newborns with $\mathrm{G}(p=0.015)$ when compared to newborns whose delivery occurred after 37 weeks of gestation in this study. The use of maternal prenatal corticosteroid was also beneficial to newborns. First enteral diet before the $10^{\text {th }}$ post-operative day $(p=0.0016)$ could be performed in both group in all maternal ages.

\section{Conflicts of Interest}

The authors declare no conflicts of interest regarding the publication of this paper.

\section{References}

[1] Ambrose, S.S. (1972) The Anterior Body Wall. In: Skandalakis, J. and Gray, S.W., Eds., Embryology for Surgeons. The Embryological Basis for the Treatment of Congenital Anomalies, 2nd Edition, WB Saunders, Philadelphia, 414-415.

[2] Aoki, Y., Ohshio, T. and Komi, N. (1980) An Experimental Study on Gastroschisis Using Fetal Surgery. Journal of Pediatric Surgery, 15, 252-256. https://doi.org/10.1016/S0022-3468(80)80131-X

[3] Sinkey, R.G., Habli, M.A., South, A.P., Gibler, W.W., Burns, P.W., Eschenbacher, M.A. and Warshak, C.R. (2016) Sonographic Markers Associated with Adverse Neonatal Outcomes among Fetuses with Gastroschisis: An 11-Year, Single-Center Review. American Journal of Obstetrics \& Gynecology, 214, 275.e1-275.e7. https://doi.org/10.1016/j.ajog.2015.09.081

[4] Vult, L.T., Nobuhara, K.K., Laurent, C. and Shaw, G.M. (2008) Increasing Prevalence of Gastroschisis: Population-Based Study in California. The Journal of Pediatrics, 152, 807-811. https://doi.org/10.1016/j.jpeds.2007.11.037

[5] Saxena, A.K., Hülskamp, G., Schleef, J., Schaarschmidt, K., Harms, E. and Willital, G.H. (2002) Gastroschisis: A 15-Year, Single-Center Experience. Pediatric Surgery International, 18, 420-424. https://doi.org/10.1007/s00383-002-0799-y

[6] Kunz, L.H., Gilbert, W.M. and Towner, D.R. (2005) Increased Incidence of Cardiac Anomalies in Pregnancies Complicated by Gastroschisis. American Journal of $\mathrm{Ob}$ - 
stetrics \& Gynecology, 193, 1248-1252. https://doi.org/10.1016/j.ajog.2005.05.080

[7] Rittler, M., Campanã, H., Ermini, M.L., Gili, J.A., Poletta, F.A., Pawluk, M.S., Giménez, L.G., Cosetino, V.R., Castilla, E.E. and López-Camelo, J.S. (2015) Gastroschisis and Young Mothers: What Makes Them Different from Other Mothers of the Same Age? Birth Defects Research Part A: Clinical and Molecular Teratology, 103, 536-543. https://doi.org/10.1002/bdra.23374

[8] Horsley, T., Binongo, J.N. and Kancherla, V. (2018) Maternal Chlamydia Infection during Pregnancy among Mothers and Risk of Gastroschisis in Singleton Offspring. Birth Defects Research, 110, 429-442. https://doi.org/10.1002/bdr2.1179

[9] Hoyme, E.W., Higginbottom, M.C. and Jones, K.L. (1981) The Vascular Pathogenesis of Gastroschisis: Intrauterine Interruption of the Omphalomesenteric Artery. The Journal of Pediatrics, 98, 228-231. https://doi.org/10.1016/S0022-3476(81)80640-3

[10] Forrester, M.B. and Merz, R.D. (2006) Comparison of Trend in Gastroschisis and Prenatal Illicit Drug Use Rates. Journal of Toxicology and Environmental Health, 69, 1253-1259. https://doi.org/10.1080/15287390500361750

[11] Di Lorenzo, M., Yazbeck, S. and Ducharme, J.C. (1987) Gastroschisis: A 15-Year Experience. Journal of Pediatric Surgery, 22, 710-712. https://doi.org/10.1016/S0022-3468(87)80610-3

[12] Vilela, P.C., Ramos, D.E., Amorim, M.M., Falbo, G.H. and Santos, L.C. (2001) Risk Factors for Adverse Outcome of Newborns with Gastroschisis in a Brazilian Hospital. Journal of Pediatric Surgery, 36, 559-564.

https://doi.org/10.1053/jpsu.2001.22282

[13] Srinathan, S.K., Langer, J.C., Blennerhassett, M.G., Harrison, M.R., Pelletier, G.J. and Lagunoff, D. (1995) Etiology of Intestinal Damage in Gastroschisis. III: Morphometric Analysis of the Smooth Muscle and Submucosa. Journal of Pediatric Surgery, 30, 379-383. https://doi.org/10.1016/0022-3468(95)90036-5

[14] Santos, M.M., Tannuri, U. and Maksoud, J.G. (2003) Alterations of Enteric Nerve Plexus in Experimental Gastroschisis: Is There a Delay in the Maturation? Journal of Pediatric Surgery, 38, 1506-1511. https://doi.org/10.1016/S0022-3468(03)00504-9

[15] França, W.M., Langone, F.F., De la Hoz, C.L., Gonçalvez, A.A., Bittencourt, D. and Pereira, L. and Sbragia, L. (2008) Maturity of the Myenteric Plexus Is Decreased in the Gastroschisis Rat Model. Fetal Diagnosis and Therapy, 23, 60-68. https://doi.org/10.1159/000109228

[16] Langer, J.C., Longaker, M.T., Crombleholme, T.M., et al. (1989) Etiology of Intestinal Damage in Gastroschisis. I. Effects of Amniotic Fluid Exposure and Bowel Constriction in a Fetal Lamb Model. Journal of Pediatric Surgery, 24, 992-997. https://doi.org/10.1016/S0022-3468(89)80200-3

[17] Tibboel, D., Vermey-Keers, C., Klünck, P., Gaillard, J.L., Koppenberg, J. and Molenaar, J.C. (1986) The Natural History of Gastroschisis during Fetal Life: Development of the Fibrous Coating in the Bowel Loops. Teratology, 33, 267-272. https://doi.org/10.1002/tera.1420330303

[18] Landisch, R.M., Yin, Z., Christensen, M., Szabo, A. and Wagner, A.J. (2017) Outcomes of Gastroschisis Early Delivery: A Systematic Review and Meta-Analysis. Journal of Pediatric Surgery, 52, 1962-1971. https://doi.org/10.1016/j.jpedsurg.2017.08.068

[19] Dunn, J.C.Y., Fonkalsrud, E.W. and Atkinson, J.B. (1999) The Influence of Gestational Age and Mode of Delivery on Infants with Gastroschisis. Journal of Pediatric Surgery, 34, 1393-1395. 
[20] Guo, W., Swaniker, F., Fonkalsrud, E.W., Vo, K. and Karamanoukian, R. (1995) Effect of Intra-Amniotic Dexamethasone Administration on Intestinal Absorption in a Rabbit Gastroschisis Model. Journal of Pediatric Surgery, 30, 983-986. https://doi.org/10.1016/0022-3468(95)90326-7

[21] Bittencourt, D.G., Barreto, M.W., França, W.M., Gonçalves, A., Pereira, L.A. and Sbragia, L. (2005) Impact of Corticosteroid on Intestinal Injury in a Gastroschisis Rat Model: Morphometric Analysis. Journal of Pediatric Surgery, 41, 547-553.

[22] Lap, C.C., Brizot, M.L., Pistsorius, L.R., Kramer, W.L., Teeuwen, I.B., Eijkemans, M.J., Brouwers, H.A., Pajkrt, E., van Kaan, A.H., van Scheltema, P.N., Eggink, A.J., van Heijst, A.F., Haak, M.C., van Weissenbruch, M.M., Sleeboon, C., Willekes, C., van der Hoeven, M.A., van Heurn, E.L., Bilardo, C.M., Dijk, P.H., van Baren, R., Francisco, R.P., Tannuri, A.C., Visser, G.H. and Manten, G.T. (2016) Outcome of Isolated Gastroschisis: An International Study, Systematic Review and Meta-Analysis. Early Human Development, 103, 209-218.

https://doi.org/10.1016/j.earlhumdev.2016.10.002

[23] Singh, S.J., Fraser, A., Leditschke, J.F., Spence, K., Kimble, R., Dalby-Payne, J., et al. (2003) Gastroschisis: Determinants of Neonatal Outcome. Pediatric Surgery International, 19, 260-265. https://doi.org/10.1007/s00383-002-0886-0 